\title{
Activated Protein C (APC) Promotes A Healing Phenotype in Cultured Murine Tenocytes Via Protease- Activated Receptor (PAR)-2, but not PAR-1
}

\author{
Callum Fryer, Christopher Jackson, Kelly McKelvey, Haiyan Lin and Meilang Xue* \\ Sutton Arthritis Research Laboratory, Kolling Institute of Medical Research, The University of Sydney at Royal North Shore \\ Hospital, St Leonards NSW 2065, Australia
}

*Corresponding author: Meilang Xue, Sutton Arthritis Research Laboratory, Kolling Institute of Medical Research, The University of Sydney at Royal North Shore Hospital, St Leonards NSW 2065, Australia

\section{ARTICLE INFO}

Received: 慧 October 19, 2021

Published: 蔧 October 29, 2021

Citation: Callum Fryer, Christopher Jackson, Kelly McKelvey, Haiyan Lin and Meilang Xue. Activated Protein C (APC) Promotes A Healing Phenotype in Cultured Murine Tenocytes Via Protease-Activated Receptor (PAR)-2, but not PAR-1. Biomed J Sci \& Tech Res 39(4)-2021. BJSTR. MS.ID.006341.

Keywords: Tenocyte; Activated Protein C; Protease Activated Receptor; Proliferation; Migration; Wound Healing

\section{ABSTRACT}

Background: Tendinopathy is a tendon pathology often resulting from a failed healing response to tendon injury. Activated protein C (APC) is a natural anti-coagulant with anti-inflammatory and wound healing promoting functions, which are mainly mediated by its receptors, endothelial protein $C$ receptor (EPCR) and protease activated receptors (PARs). This study aimed to determine whether APC stimulates tenocyte healing and if so, to assess the involvement of the receptors.

Methods: Mouse-tail tenocytes were isolated from 3-week-old wild type (WT), PAR1 knockout (KO) and PAR-2 KO mice. The expression of EPCR, PAR-1 and -2 and the effect of APC on tenocytes tendon healing and the underlying mechanisms were investigated by Reverse transcription real time PCR, western blot, 3- (4,5-dimethylthiazol-2-yl)-2,5diphenyltetrazolium bromide (MTT) assay, zymography, and scratch wound healing/ migration assay.

Results: When compared to WT cells, PAR-1 KO tenocytes showed increased cell proliferation (3.3-fold, $\mathrm{p}<0.0001)$, migration $(2.7$-fold, $\mathrm{p}<0.0001)$ and wound healing (3-fold, p<0.0001), whereas PAR-2 KO cells displayed decreased cell proliferation $(0.6$-fold, $\mathrm{p}<0.05)$ and no change in cell migration or wound healing. APC at $1 \mu \mathrm{g} / \mathrm{ml}$ stimulated WT and PAR-1 KO tenocyte proliferation $(\sim 1.3$, respectively, $\mathrm{p}<0.05)$ and wound healing $(\sim 1.3$-fold, respectively, $p<0.05)$, and additionally promoted PAR1-KO cell migration (1.4-fold, $p<0.0001)$. APC only increased the migration $(2$-fold, $p<0.05)$ of PAR-2 KO tenocytes. The activation of AKT, extracellular signal-regulated kinase (ERK)-2, and glycogen synthase kinase (GSK)- $\beta 3$, the intracellular molecules that are associated with cell survival/growth, and matrix metalloproteinase (MMP)-2 that is related to cell migration and wound healing, were increased in all three cell lines in response to APC treatment.

Conclusion: These findings show that PAR- 1 and PAR- 2 act differentially in tenocyte proliferation/migration/wound healing. APC likely promotes tenocyte proliferation/ wound healing via PAR-2, not PAR-1.

Abbreviations: APC: Activated Protein C; ANOVA: Analysis of Variance; ApoER2: Apolipoprotein E Receptor 2; DMEM: Dulbecco's Modified Eagle's Medium; EPCR: Endothelial Protein C Receptor; ERK: Extracellular Signal-Regulated Kinase; GSK: Glycogen Synthase Kinase; FBS: Foetal Bovine Serum; KO: Knockout; MMP: Matrix Metalloproteinase; MAPF: Mitogen-activated Protein Kinase; NF: Nuclear Factor; RANKL: Receptor Activator of Nnuclear Factor-kappa B Ligand; S1P: Sphingosine 1-phosphate; SD: Standard Deviation; P: Phosphorylated; PCR: Polymerase Chain Reaction; PAR: Protease Activated Receptor: RT: Reverse Transcription; WT: Wild Type: MTT: 3- (4,5-dimethylthiazol-2-yl)-2,5-Diphenyltetrazolium Bromide 


\section{Background}

Tendon is the connective tissue that transmits the force from muscle to bone to facilitate joint movement. Healthy tendon is comprised of fibroblast-like tenocytes between parallel collagen fibres. Injury to a tendon triggers an ordered triphasic healing response: (i) Inflammation, (ii) Repair and (iii) Remodeling [1]. Hindrance to these sequential stages can halt the healing cascade, leading to tendinopathy.

'Tendinopathy' is a non-specific term used to describe pathology in, and/or pain arising from a tendon. Indications of tendinopathy include collagen disorganization, increased cellularity and a poor tendency to heal [2,3]. Tendon injuries cause considerable morbidity in the general adult population [4]. The ideal treatment for tendinopathy is yet to be elucidated and should be focused on elucidating the key functional pathways implicated in the disease [5]. Activated protein C (APC) is an endogenous serine protease of physiological importance due to its potent anti-coagulant, anti-inflammatory and cytoprotective properties [6]. Protein C is mostly produced by the liver and is secreted to the blood where it is activated to APC when bound to the thrombin-thrombomodulin complex. Endothelial protein $\mathrm{C}$ receptor (EPCR) can enhance this activation. Once activated, APC exerts either its anti-coagulant activity, or while still bound to EPCR it can cleave protease activated receptors (PARs) to elicit cytoprotective effects via numerous signaling pathways, including inhibition of the nuclear factor (NF)$\kappa \mathrm{B}$, and activation of the mitogen-activated protein (MAP) kinase and glycogen synthase kinase (GSK)- $\beta 3$ pathways [7]. PAR-1 and PAR-2 have been found to be vital to cell functions in various body systems including musculoskeletal system $[8,9]$, the nervous system [10], cardiovascular system [11], respiratory system [12,13], as well as the integumentary system [14-24].

In a previous study, APC has been shown to stimulate a healing phenotype in sheep tenocytes via the EPCR [25]. APC increased tenocyte proliferation, matrix metalloproteinase (MMP)-2 activity and collagen type I deposition in a dose and time dependent manner [25]. Additionally, the MAP kinase pathway was proposed to be involved; APC dose-dependently stimulated phosphorylated (P)extracellular signal-regulated kinase (ERK)-2 and inhibited P-p38 [25]. Whilst APC has been shown to exert some of these effects on tenocytes via EPCR, whether and how PARs are involved remains to be elucidated. Understanding the molecular mechanisms of APC is crucial in maximizing its therapeutic potential in tendinopathy.

\section{Methods}

\section{Aim}

The aim of this study was to determine whether APC stimulates murine tenocyte healing and if so, to assess the involvement of the receptors and underlying mechanisms in vitro.

\section{Cell Isolation, Culture and Treatment}

Three weeks old female wild type (WT), PAR-1 knock out (KO) or PAR-2 KO mice (all are with a C57 background) were bred and obtained from Kearns Facility, Kolling Institute, University of Sydney. 6 mice were used for each gene knockout with a total of 18 mice used. Mice were euthanized by a trained, individually; separate from animal room, in a visible chamber, with $100 \%$ carbon dioxide with a fill rate of $70 \%$ of the chamber volume per minute. Mice were observed for cessation of respiration within 2 minutes and carbon dioxide flow continued for another 1 minute thereafter. After euthanized, mouse-tail skin was physical peeled back; tendon stripped off and cut into an amorphous mass of small pieces. Tenocytes were extracted from the tail tendon using a $0.2 \%$ Type 1 collagenase digestion medium and then cultured in Dulbecco's modified Eagle's medium (DMEM) containing $10 \%$ foetal bovine serum (FBS), $100 \mathrm{U} / \mathrm{mL}$ penicillin and $100 \mu \mathrm{g} / \mathrm{mL}$ streptomycin. The unused mouse tissues were cremated and discarded. Confirmation of complete deletion of PAR-1 and PAR-2 at the gene level was further achieved by reverse transcription (RT)-PCR. After confluency, cells were trypsinized, reseeded into individual 24-well culture plates, and grew. When approximately $90 \%$ confluency was reached, cells were switched to serum free DMEM overnight, then changed to fresh serum free DMEN and treated with recombinant human APC (Eli Lilly, Indianapolis, Indiana USA).

After treatment, culture supernatants were collected for zymography and cells were lysed by NET lysis buffer $(100 \mathrm{mM}$ $\mathrm{NaCl}, 1 \mathrm{mM}$ EDTA, 20 mM Tris, $0.5 \%$ Triton X100) supplemented with protease and phosphatase inhibitors (Roche, Sydney NSW Australia) for western blot. Cells from passages 1 to 4 were used in experiments. Royal North Shore Hospital Animal Ethics Committee approved usage of mouse tissues. All experiments were performed three times.

\section{Gelatin Zymography}

MMP-2 and MMP-9 protein secretion and activation in the cell culture supernatants were detected by gelatin zymography under non-reducing conditions, as described previously [26]. In brief, the proteins were separated by electrophoresis under non reducing conditions with gelatin retained in the gel. After electrophoresis, the gel was renatured with Triton ${ }^{\circledR} \mathrm{X}-100$, and subsequently developed in an appropriate activation buffer. During this development, the concentrated, renatured MMPs in the gel digested the substrate. After incubation, the gel was stained with Coomassie ${ }^{\circledR}$ Blue, and the MMPs were detected as clear bands against a blue background of undegraded substrate. The clear bands in the gel were then quantified by densitometry. 


\section{Western Blotting}

The expression and activation of ERK1/2, AKT and GSK- $\beta 3$ by tenocytes were investigated by Western blotting as described previous [25] $\beta$-actin was included to assess equal loading.

\section{MTT Assay}

Tenocyte proliferation was assessed by the 3(4,5-dimethylthiazol-2-yl)-2,5-diphenyltetrazolium bromide (MTT) assay. Cells were counted and seeded in a 96-well plate with 200 $\mu \mathrm{l}$ of $10 \%$ FBS in DMEM. After overnight attachment, the medium was replaced with fresh $2 \%$ FCS DMEM and APC treatments were applied. Cells were incubated at $37{ }^{\circ} \mathrm{C}$ for a total of $72 \mathrm{hrs}$. Three hrs prior to termination of the experiment, $10 \mu \mathrm{l}$ of $2 \mathrm{mg} / \mathrm{mL}$ MTT solution was added to each well. After $3 \mathrm{hrs}$ incubation, the medium was removed and replaced with $100 \mu \mathrm{l}$ of dimethyl sulfoxide. The colour change resulting from the solubilisation of formazan crystals was quantified using a microplate spectrophotometer (BioRad) operating at $570 \mathrm{~nm}$. A baseline reading was also taken at $630 \mathrm{~nm}$ to minimize background interference.

\section{Scratch Wound Assay}

Tenocyte migration was examined via a scratch assay. Cells were counted and seeded into 24 -well plates and grown to $70 \%$ confluency. One vertical line was scratched down the center of each well using the point of a sterile $1 \mathrm{~mL}$ pipette tip, creating a cellfree "wound" area approximately $2 \mathrm{~mm}$ in width. To standardize the position of the wound when photographing, small indents were made in the well using a sterile $31 \mathrm{G}$ needle. Cells were washed twice with $1 \mathrm{~mL}$ of media to flush away any suspended cells. Cells were then starved in $2 \%$ FBS DMEM and photos immediately taken. To distinguish the contribution of proliferation to the migration of tenocytes into the "wound" area, cells were pre-treated with mitomycin C (10 $\mu \mathrm{g} / \mathrm{mL}$, Sigma, Aldrich) 2 hrs before "wounding" to inhibit proliferation. Cells were then treated with $1 \mu \mathrm{g} / \mathrm{mL}$ APC and photos were taken again after $24 \mathrm{hr}$. Cell migration was determined by calculating the fold change of cells that migrated into wound areas in 24 hours by:

$$
\text { Fold change of cellmigration }=\frac{\text { Number of migrated cells treated withagent }}{\text { Number of migrated cellstreated without treatment }}
$$

\section{mRNA Isolation and Quantitative Real Time PCR}

mRNA was isolated using RNAzol RT Isolation Reagent (Molecular Research Center, Cincinnati, OH USA). Primers for EPCR, PAR-1 and PAR-2 were designed and checked for specificity using the National Center for Biotechnology Information BLAST search tool [27]. The murine primer sequences for EPCR (NM_011171.2: 183bp) were 5"-ATCTGACCCAGTTCGAAAGC-3" (forward) and 5"GGCCGGAAACTTACAAAAGC-3" (reverse); PAR-1 (NM_010169.3; 199bp) were 5"- ACTTCACTTGCGTGGTCATT -3" (forward) and 5"GAAACGATCAACGGCACAAG-3" (reverse); PAR-2 (NM_007974.4; $164 \mathrm{bp}$ ) were 5"-CCTTACTGCATCTGCCTACG-3" (forward) and 5"- AATGCACTACGAGCAGAAGG -3" (reverse). RT Quantitative PCR was performed to determine the amounts of EPCR, PAR- 1 and PAR2 gene expression in tenocytes from WT, PAR-1 KO and PAR-2 KO mice (The Rotor-Gene 6000 Real-Time PCR machine, Corbett Life Science, Mortlake Australia). Data were analysed using the relative quantification method, and results expressed as fold change $(\Delta \mathrm{Rn})$ relative to wild type (WT) untreated samples. $\beta$-Actin housekeeping gene expression was used to normalize mRNA levels of PAR-1, PAR2 and EPCR.

\section{Statistical Analysis}

All data was expressed as mean \pm standard deviation (SD). Results were analysed using one-way analysis of variance (ANOVA), in combination with and followed by Tukey post-hoc test. GraphPad Prism software was used for statistical computations. A p-value < 0.05 was considered statistically significant.

\section{Results}

\section{Gene Expression of EPCR, PAR-1 or PAR-2 in WT, PAR-1 and PAR-2 KO Cells}

A homogenous cell population was obtained and morphologically identified as fibroblast-like cells. Spindle-shaped contours were observed using inverted phase-contrast microscopy (Figure 1A). Tenocytes from $3 \mathrm{w} / \mathrm{o}$ mice demonstrated that, as expected, PAR-1 KO cells had no expression of PAR-1 and PAR-2 KO cells had no expression of PAR-2 (data not shown). Interestingly, expression of PAR-1 by PAR-2 KO cells did not change whereas PAR-2 expression was increased 2.7 folds by PAR- 1 KO cells. EPCR expression was stimulated in both PAR-1 KO and PAR- 2 KO cells (Figures 1B-1D). In WT cells, EPCR, PAR-1 and PAR-2 expression showed a dose-dependent response to APC treatment. There were 1.6 and 2-fold increases $(\mathrm{p}<0.05)$ in EPCR expression in response to APC at 1 and $10 \mu \mathrm{g} / \mathrm{mL}$, respectively (Figure 1D); a 2.7-fold increase in PAR-1 expression and a 2.7 -fold increase $(\mathrm{p}<0.05)$ in PAR-2 expression at $10 \mu \mathrm{g} / \mathrm{mL}$ APC by WT tenocytes (Fig. 1B\&C). However, the expression of PAR-2 and EPCR by PAR-1 KO tenocytes or the expression of PAR-1 and EPCR by PAR-2 KO tenocytes did not display a statistically significant response to APC treatment (Figures 1B-1D). This data indicates that APC can regulate its receptor expression, while knockout PAR-1 or PAR-2 abolishes this effect of APC. 


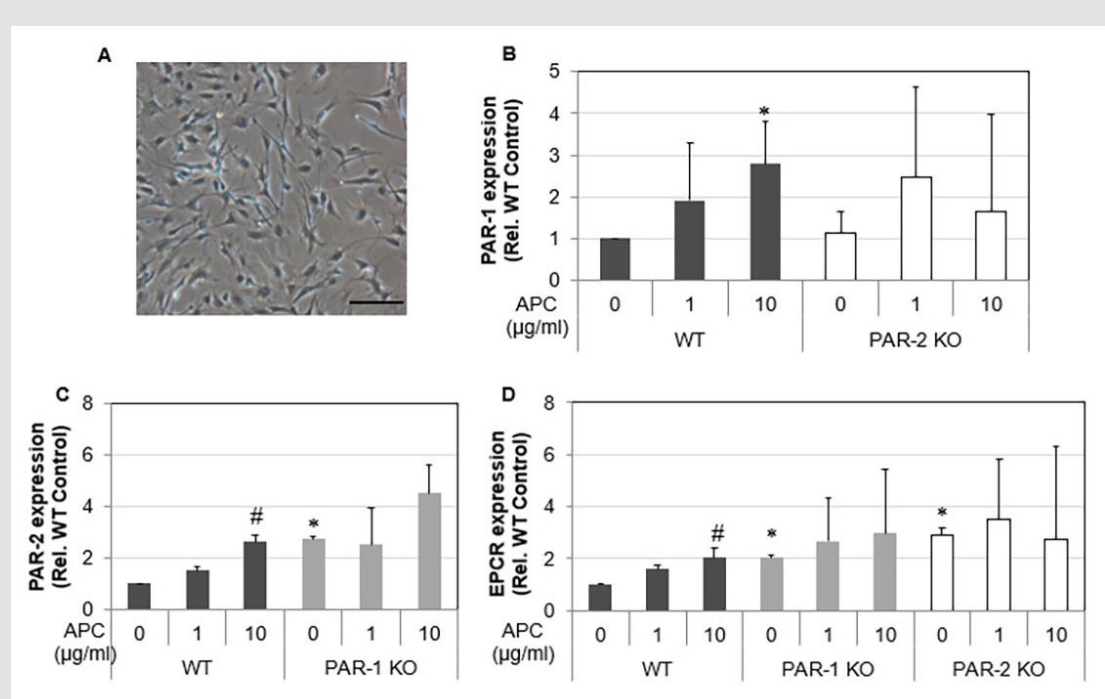

Figure 1: The gene expression of EPCR, PAR-1 and PAR-2 in WT, PAR-1 KO and PAR-2 KO tenocytes in response to APC. Note: Tenocytes at passage 1 from 3 w/o WT, PAR-1 KO and PAR-2 KO mice were treated with APC (1, $10 \mu \mathrm{g} / \mathrm{ml})$ for $24 \mathrm{hrs}$.

A) Micrograph of tenocytes growing from collagenase digestion tendon at passage 1. Scale bar: $100 \mu \mathrm{m}$.

B) Gene expression of PAR-1 in WT and PAR-2 KO tenocytes.

C) Gene Expression of PAR-2 in WT and PAR-1 KO tenocytes.

D) Gene expression of EPCR in WT, PAR-1 KO and PAR-2 KO tenocytes. Quantitative RT-PCR of EPCR, PAR-1 and PAR-2 expression in tenocytes normalized to $\beta$-actin. Bars show mean $\pm \operatorname{SD}(n=3)$. ${ }^{*} p<0.05$ vs WT Control and \#p< 0.05 vs their own controls, one-way ANOVA calculated using Tukey post-hoc analysis.

\section{Proliferation and Migration of Tenocytes}
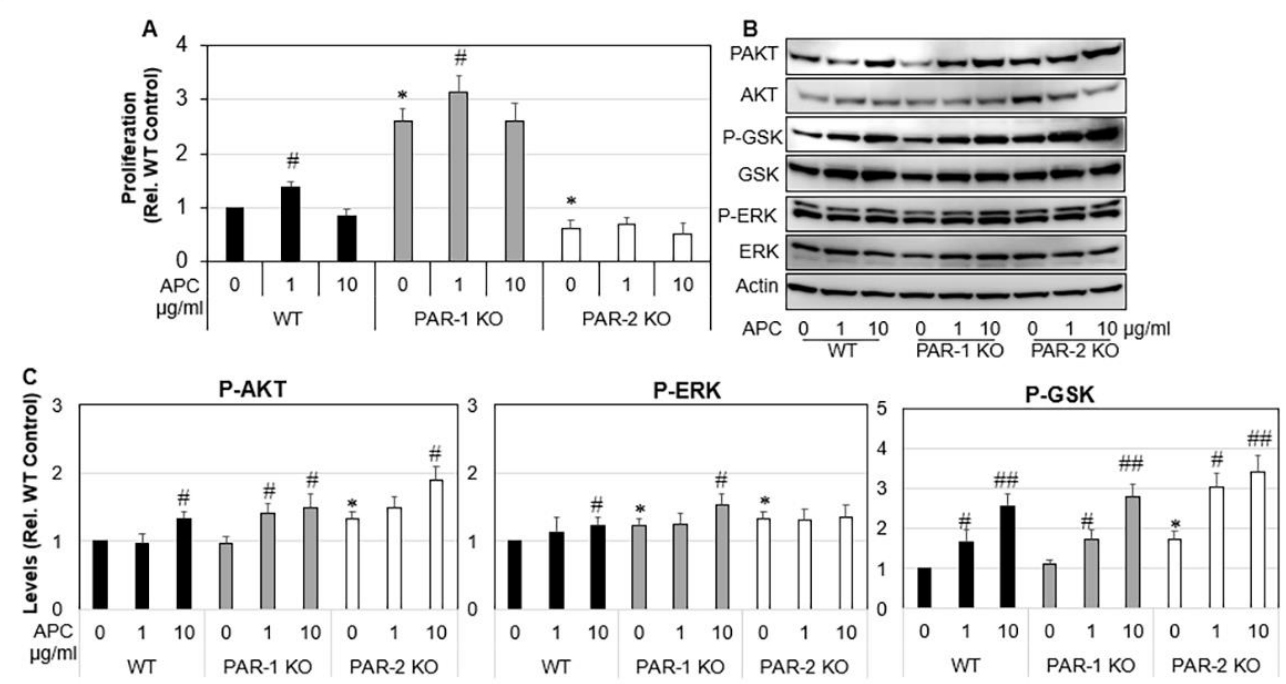

Figure 2: Proliferation and MAP Kinase expression of WT, PAR-1 KO and PAR-2 KO tenocytes in response to APC. Note: WT, PAR-1 KO and PAR-2 KO tenocytes were treated with APC $(1,10 \mu \mathrm{g} / \mathrm{ml})$ for either 24 hrs or 72 hrs.

A) Tenocyte proliferation assessed 72 hrs after APC treatment by MTT assay.

B) Expression and activation of ERK, AKT and GSK- 33 24hrs after APC treatment detected by Western blot.

C) Data are semi-quantitation by Image J and depicted in the graph as fold change relative to control. Results shown are mean $\pm \mathrm{SD}(\mathrm{n}=3){ }^{*} \mathrm{p}<0.05$ vs WT Control and \# $\mathrm{p}<0.05$ vs their own controls (no treatment), one-way ANOVA calculated using Tukey post-hoc analysis. \#\#P<0.01. 
Cell proliferation and migration are vital for tendon healing Under basal conditions, proliferation of PAR-1 KO tenocytes was increased by 3.3-fold compared WT tenocytes (Figure 2A), $\mathrm{p}<0.0001)$. In contrast, PAR-2 KO tenocytes showed a 0.6-fold decrease in proliferation when compared to WT control. APC promoted proliferation of WT tenocytes by $\sim 1.3$-fold $(\mathrm{p}<0.05)$, PAR1 KO tenocyte by 1.2 -fold $(\mathrm{p}<0.05$ ) (Figure $2 \mathrm{~A}$ ) at $1 \mu \mathrm{g} / \mathrm{ml}$ when compared to their own controls (Figure 2A). APC had no significant effect on the proliferation of PAR-2 KO tenocytes (Figure 2A). These results suggest that APC dose-dependently promotes tenocyte proliferation, similar to other cells showed previously [28], and this stimulating effect is likely via PAR-2. To investigate the underlying mechanisms, western blot was performed to examine the activation of ERK, AKT and GSK- $\beta 3$, three intracellular molecules that associated with cell proliferation/survival [7,29-32]. Compared to WT, activated forms of ERK, AKT and GSK- $\beta 3$ were significantly higher in PAR-2 KO cells (Figures 2B \& 2C). APC stimulated the activation of AKT and GSK- $\beta 3$ in all primary cells, and the activation of ERK in WT and PAR-1 KO cells (Figures 2B \& 2C).

Similar to proliferation, unstimulated PAR-1 KO tenocytes showed a 2.7-fold $(\mathrm{p}<0.0001)$ increase in cell migration compared to WT cells, whereas PAR-2 KO tenocytes did not differ from WT control. APC (1 $\mu \mathrm{g} / \mathrm{mL})$ had no effect on WT tenocyte migration (Figures 3A \& 3B), but stimulated PAR-1 KO tenocyte migration by 1.4 -fold $(\mathrm{p}<0.0001)$ and PAR-2 KO tenocytes migration by 2.1fold $(\mathrm{p}<0.001)$, when compared to their own controls (Figures $3 \mathrm{~A} \& 3 \mathrm{~B})$. Wound healing is a combined effect of cell migration and proliferation. As expected, wounds created in PAR-1 KO cell monolayers healed 3-fold faster than WT cells (Figure 3C), whereas wounds on PAR-2 KO cell monolayers healed at a similar rate to that by WT control. APC at $1 \mu \mathrm{g} / \mathrm{ml}$ promoted $\sim 1.3$-fold increase in wound healing by PAR-1 KO and WT by not PAR-2 KO cells (Figure 3C).
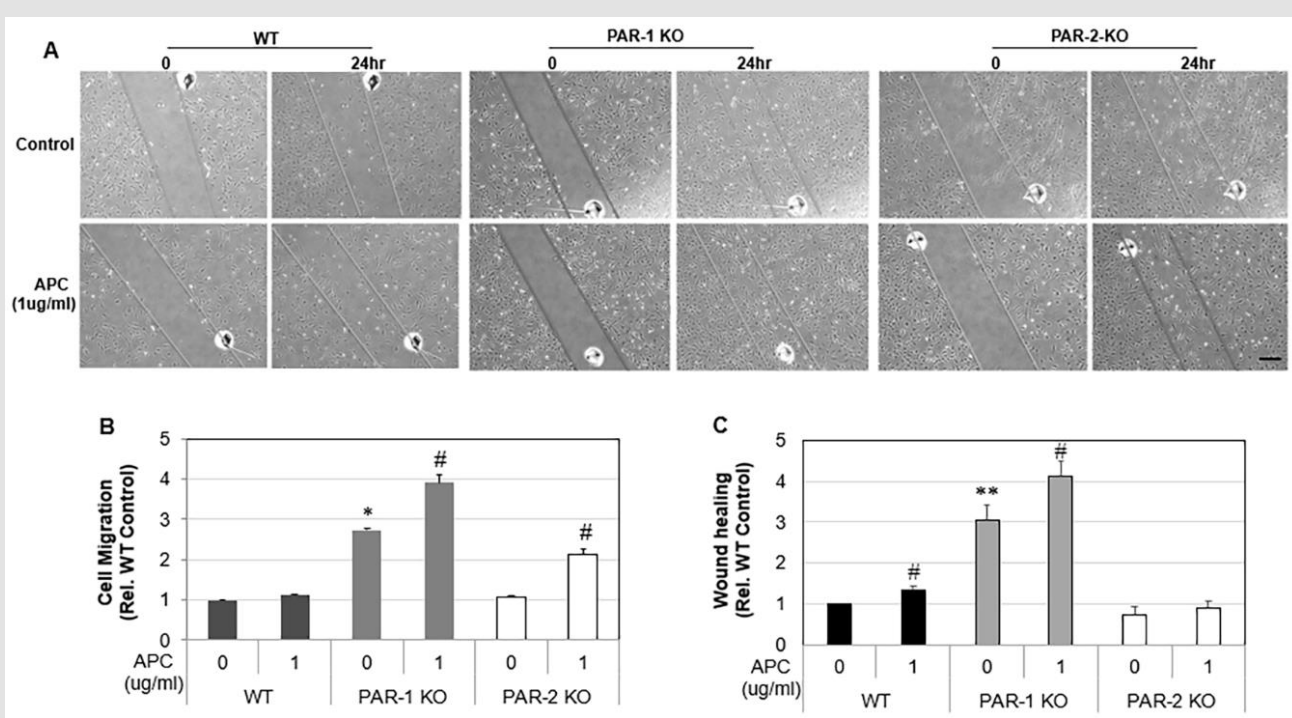

Figure 3: Migration and wound healing of WT, PAR-1 KO and PAR-2 KO tenocytes in response to APC. Note: WT, PAR-1 KO and PAR-2 KO Tenocytes were treated with APC for 24 hrs.

A) Representative images of migration assay.

B) Tenocyte migration assessed $24 \mathrm{hrs}$ after APC treatment $(1 \mu \mathrm{g} / \mathrm{ml})$ by a scratch assay.

C) Tenocyte wound healing assessed $24 \mathrm{hrs}$ after APC treatment $(1 \mu \mathrm{g} / \mathrm{ml})$ by a scratch assay. Results are expressed as mean \pm SD $(n=2)$. Scale bar: $250 \mu \mathrm{m}$. * $p<0.05$ vs WT Control and $\# p<0.05$ vs their own controls, one-way ANOVA calculated using

Tukey post-hoc analysis. ${ }^{* *} \mathrm{p}<0.01$.

\section{MMP-2 and MMP-9 Expression by Tenocytes}

MMP-2 and MMP-9 aid the remodeling phase of healing by contributing to the turnover of collagen and extracellular matrix, and cell migration in many cell types [8,33-35]. Gelatin zymographical data showed that WT tenocytes displayed a dose response increase in MMP-2 expression and activation from 0.1 to $10 \mu \mathrm{g} / \mathrm{mL}$ of APC (Figure $4 \mathrm{~A}$ ). There was a 1.5 -fold increase $(\mathrm{p}<0.05)$ in MMP-2 expression and 1.7-fold increase $(\mathrm{p}<0.01)$ in total MMP-2 at $10 \mu \mathrm{g} / \mathrm{mL}$ APC compared to the control (Figure $4 \mathrm{~A}$ ). APC increased MMP-2 in WT, PAR-1 KO and PAR-2 KO. APC had no effect on WT MMP-9, however, increased MMP-9 expression in PAR1 KO cells. PAR-2 KO cells showed decreased MMP-9 expression. These findings show APC increases MMP-2 by PAR-1 and PAR-2, however decreases MMP-9 via PAR-1 and increases MMP-9 via PAR2 in murine tenocytes. 

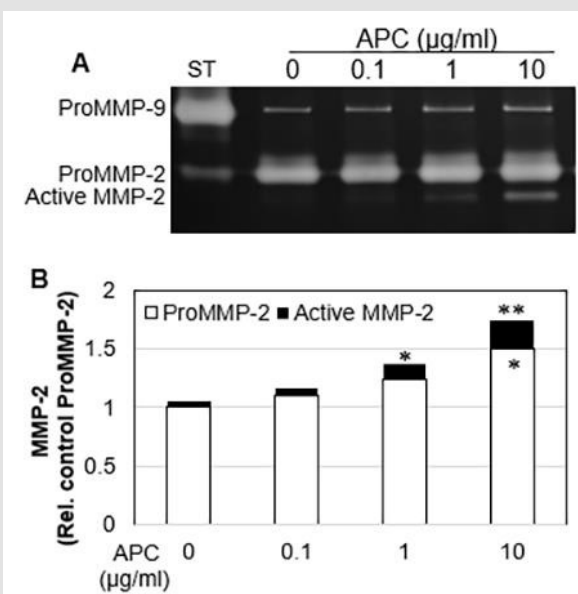
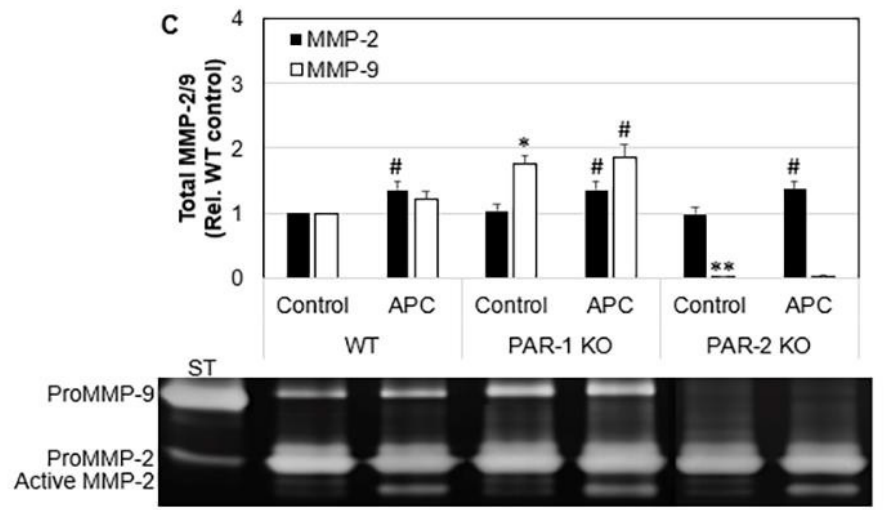

Figure 4: The expression and activation of MMP-2 in WT, PAR-1 KO and PAR-2 KO tenocytes in response to APC. Note: WT, PAR-1 KO and PAR-2 KO Tenocytes were treated with APC for 24 hrs.

A) MMP-2 expression/activation in WT cell culture supernatants, detected by zonography. Data are semi-quantitation by Image $\mathrm{J}$ and depicted in the graph as fold change relative to control.

B) Total MMP-2 and MMP-9 in cell culture supernatants, comparing treatment with APC, detected by zymography. Data are semi-quantitation by Image J and depicted in the graph as fold change relative to control. Results shown are mean \pm SD ( $\mathrm{n}=3$ ) ${ }^{*} \mathrm{p}<0.05$ vs WT Control and \# $\mathrm{p}<0.05$ vs their own controls, one-way ANOVA calculated using Tukey post-hoc analysis. ${ }^{* *}$ or $\# \# \mathrm{p}<0.01$.

\section{Discussion}

APC is an endogenous serine protease of physiological importance. It has potent anti-coagulant, anti-inflammatory, antiapoptotic and cytoprotective properties. The therapeutic potential of APC has been demonstrated in wide variety of pathologies including sepsis, wound healing, ischemic stroke, lung disorders, kidney injury, diabetic nephropathy, inflammatory bowel disease, systemic lupus erythematosus, amyotrophic lateral sclerosis and cancer metastasis [36-41]. The therapeutic effects of APC on tendon healing have been far less studied. In the only previous study of tenocytes, APC increased tenocyte proliferation, MMP-2 activity, type I collagen deposition and stimulated a healing phenotype in sheep tenocytes [25]. The actions of APC are largely via binding to EPCR, which subsequently activates PAR-1 [42]. However, APC promoted murine skin wound healing via PAR-2, but not via PAR1 [43]. Whether and how APC via these receptors mediates the tenocyte healing phenotype has not previously been investigated. In the current study, we demonstrated that deletion of PAR-1 increased tenocyte proliferation, migration and wound healing, whereas deletion of PAR-2 decreased tenocyte proliferation and has no effect on cell migration or wound healing when compared to WT cells; PAR-1 KO and PAR-2 KO cells exhibit increased EPCR expression; APC enhances tenocyte proliferation, migration and wound healing in WT or PAR-1 KO cells, and had limited effect in PAR-2 KO cells. These data indicate that APC promotes tenocyte proliferation and migration by PAR-2, not PAR-1.
Tenocyte proliferation and migration are vital stages of tendon repair [1]. In this study, PAR-1 and PAR-2 displayed differential functions on these two events in mouse tenocytes. This is consistent with a previous study which showed that PAR-2 knockout mice healed significantly slower than wild-type mice and this delayed healing was not altered by adding APC, indicating that APC acts through PAR-2 to heal murine wounds [43]. Similarly, PAR-2 but not PAR-1 modulates synovial macrophage maturation in posttraumatic osteoarthritic mice and thus may play a critical role in the initiation of patient Osteoarthritis [8], and PAR-2 KO mouse synovial fibroblasts exhibited slower rates of proliferation and invasion of than normal cells [9]. These differential functions of PAR-1 and PAR2 have also been found in other types of cells or diseases. PAR-1 activation promotes proliferation of human keratinocytes [14] and dermal fibroblasts [15]. It has been shown blocking PAR-1 inhibits APC-induced proliferation in human keratinocytes and thus PAR1 appears to promote anti-apoptotic and neuroprotective effects $[16,17]$. In contrast, PAR-2 affects keratinocyte differentiation, maintains the epidermal barrier, regulates inflammation [18-22] and pain perception [23], and has a tumor-protective role in the skin [24]. In relation to the nervous system, PAR-1 has been shown to mediate mechanisms underlying astrogliosis, vital after brain injury [10].

In regards to the respiratory system, PAR-1 contributes to protective effects of APC on vascular barrier integrity [12] whereas PAR-2 increases ciliary beating which is vital against inhaled 
pathogens [13]. Additionally, for the cardiovascular system, PAR-1 KO mice have shown an absence of APC's protective effects against myocardial ischemia/reperfusion injury via inhibition of apoptosis and inflammation [11]. It was found that APC stimulated murine ectopic bone volume and enhances angiogenesis in a model of Bone Morphogenetic Protein 2 induced bone formation. Mechanistically, APC enhances cell proliferation and activates a number of canonical kinase pathways in a PAR1-dependent manner [44]. In comparison, APC induced PAR-1 signaling was shown to regulate the retention and recruitment of EPCR expressing mice bone marrow hematopoietic stem cells [45]. APC was shown to suppress RANKL-induced human osteoclast differentiation mediated through EPCR, PAR-1, S1P receptor, and ApoER2 [46]. While the noted studies above describe different effects of PAR-1 and PAR-2, it must be highlighted that the outcome of PAR activation by the same protease or synthetic agonist can also vary between tissues and cell types [47]. Therefore, the therapeutic role of APC via PARs extends and differs thorough a number of different studies and cell types.

The remodeling stage of tendon healing is predominantly achieved by tissue-degrading enzymes, MMPs [33,48,49]. MMP-9 degrades the ECM days after injury, while MMP-2 participates in both the ECM degradation and remodeling throughout the healing process [34,50,51]. MMP-2 has been associated with increased angiogenesis in in vitro and in vivo studies, however the role of MMP-9 is less distinct [35]. As a result, APC increasing MMP-2/9 activity/expression in PAR-1 KO tenocytes may prove vital in stimulating extracellular matrix degradation, angiogenesis and ultimately tendon healing. Other studies [52] have suggested the APC pathway is a potential target for prevention of MMP-2/-9/-13 activation and cartilage extracellular matrix degradation in patients with $\mathrm{OA}$

The MAPK pathway is essential in regulating key cellular activities including mitogenesis, motility, and survival in many cell types [7]. Although associated with cancer development, distinct MAP kinases including ERK, AKT and GSK- $\beta 3$ are essential for proliferation and the normal tissue repair process [30-32]. In previous studies, APC has been shown to cleave PARs to elicit cytoprotective effects via numerous signaling pathways, including the MAPK Pathways [29]. In this study, APC stimulated the activation of AKT and GSK in all 3 cell lines, and the activation of ERK in WT and PAR-1 KO cells. This may help explain why PAR$1 \mathrm{KO}$ mice showed greater cell proliferation. Another study Xue, et al. [25] found that APC dose-dependently stimulated/inhibited ERK/p38 signaling in sheep tenocytes at 24 hours, respectively. It is feasible that MAP kinase signaling in response to APC is different in different species and at different time frames post treatment, being $1 \mathrm{hr}$ in our study.

Since tendinopathy can be both hyper- or hypo-cellular [53], fine-tuning the balance between APC's interaction between PAR-1 and PAR-2 could help regulate tenocyte equilibrium. These finding could be vital as a large body of evidence suggests the promise of regenerative medicine will be achieved by focusing on augmenting the natural healing response, where little is known about the synergistic and antagonistic interactions of growth factors and perhaps their receptors to produce the best effects $[54,55]$.

\section{Conclusion}

We demonstrated that depletion of PAR-1 increased tenocyte proliferation, migration and wound healing, whereas depletion of PAR-2 only decreased cell proliferation and had no impact on cell migration or wound healing when compared to WT cells. Depletion of PAR-1 or PAR-2 increased EPCR expression, but has no effect on either PAR-2 or PAR-1 expression. APC enhanced tenocyte proliferation only in WT or PAR-1 KO cells, not in PAR-2 KO cells; promoted migration and wound healing in PAR-1 KO cells; and increased migration only in PAR-2 KO cells. These findings suggest that APC promotes tenocyte proliferation, migration and wound healing largely by PAR-2, and not PAR-1. APC increases MMP-2 by PAR-1 and PAR-2, however, decreased MMP-9 via PAR1 and increases MMP-9 via PAR-2 in murine tenocytes. Overall, APC promotes a healing phenotype in cultured murine tenocytes largely via PAR-2, no PAR-1. By shedding light on APC's therapeutic mechanistic action through PARs, this work has laid the initial platform in maximizing APC's potential in improving tenocyte healing and treating tendinopathy.

\section{Declarations}

Ethics approval and consent to participate: Use of mouse tissue was approved by Royal North Shore Hospital Ethical Committee.

\section{Consent for Publication}

Not applicable.

\section{Availability of Data and Materials}

The datasets used and/or analyzed during the current study are available from the corresponding author on reasonable request.

\section{Competing Interests}

Associate Professor Christopher Jackson and Associate Professor Meilang Xue are shareholders in a company testing APC in cutaneous wound healing. No other listed authors have any professional or financial affiliation with APC or PARs.

\section{Funding}

No specific funding for this study.

\section{Authors' Contribution}

CF performed experiments, analyzed and collated results, and wrote the article. KM contributed to the analysis and interpretation of data, helped with critically revising the paper. MX contributed 
to research design as well as the acquisition, analysis and interpretation of data, helped with the drafting and, helped with critically revising the paper. $\mathrm{CJ}$ contributed to research design as well as the acquisition, analysis and interpretation of data, and helped with critically revising the paper. HL performed experiments, analyzed and collated results.

\section{Acknowledgement}

Sources of technical support include Agnes Chan.

\section{Trial Registration}

Not applicable.

\section{References}

1. James R, Kesturu G, Balian G, Chhabra AB (2008) Tendon: Biology, Biomechanics, Repair, Growth Factors, and Evolving Treatment Options. Journal of Hand Surgery 33(1): 102-112.

2. Khan KM, Cook JL, Bonar F, Harcourt P, Åstrom M (1997) Histopathology of Common Tendinopathies. Sports Medicine 27(6): 393-408.

3. Maffulli N, Barrass V, Ewen S (2000) Light Microscopic Histology of Achilles Tendon Ruptures: A Comparison with Unruptured Tendons. The American journal of sports medicine 28: 857-863.

4. Aicale R, Tarantino D, Maffulli N (2017) Basic Science of Tendons. In: Gobbi A, Espregueira Mendes J, Lane JG, Karahan M (Eds.)., Bioorthopaedics: A New Approach. Berlin, Heidelberg: Springer Berlin Heidelberg, pp. 249-273.

5. Millar NL, Silbernagel KG, Thorborg K, Kirwan PD, Galatz LM, et al. (2021) Tendinopathy. Nature Reviews Disease Primers 7(1): 1.

6. Jackson C, Whitmont K, Tritton S, March L, Sambrook P, et al. (2008) New therapeutic applications for the anticoagulant, activated protein C. Expert Opinion on Biological Therapy 8(8): 1109-1122.

7. Roux PP, Blenis J (2004) ERK and p38 MAPK-activated protein kinases: A family of protein kinases with diverse biological functions. Microbiol Mol Biol Rev 68(2): 320-344.

8. Jackson MT, Moradi B, Zaki S, Smith MM, McCracken S, et al. (2014) Depletion of Protease-Activated Receptor 2 but Not Protease-Activated Receptor 1 May Confer Protection Against Osteoarthritis in Mice Through Extra cartilaginous Mechanisms. Arthritis \& Rheumatology 66(12): 3337-3348.

9. Xue M, Chan YKA, Shen K, Dervish S, March L, et al. (2012) Proteaseactivated receptor 2 , rather than protease-activated receptor 1 , contributes to the aggressive properties of synovial fibroblasts in rheumatoid arthritis. Arthritis \& Rheumatism 64(1): 88-98.

10. Nicole O, Goldshmidt A, Hamill CE, Sorensen SD, Sastre A, et al. (2005) Activation of Protease-Activated Receptor-1 Triggers Astrogliosis after Brain Injury. The Journal of Neuroscience 25(17): 4319-4329.

11. Wang J, Yang L, Rezaie AR, Li J (2011) Activated protein C protects against myocardial ischemic/reperfusion injury through AMP-activated protein kinase signaling. Journal of thrombosis and haemostasis: JTH 9 (7): 1308-1317.

12. Schuepbach RA, Feistritzer C, Fernández JA, Griffin JH, Riewald M (2009) Protection of vascular barrier integrity by activated protein $\mathrm{C}$ in murine models depends on protease-activated receptor-1. Thromb Haemost 101(4): 724-733.

13. McMahon DB, Workman AD, Kohanski MA, Carey RM, Freund JR, et al. (2018) Protease-activated receptor 2 activates airway apical membrane chloride permeability and increases ciliary beating. FASEB J 32(1): 155167.

14. Xue M, Campbell D, Sambrook PN, Fukudome K, Jackson CJ (2005) Endothelial Protein C Receptor and Protease-Activated Receptor-1 Mediate Induction of a Wound-Healing Phenotype in Human Keratinocytes by Activated Protein C. Journal of Investigative Dermatology 125(6): 1279-1285.

15. Duitman JW, Ruela-de-Sousa RR, Shi K, De Boer OJ, Borensztajn KS, et al. (2014) Protease Activated Receptor-1 Deficiency Diminishes BleomycinInduced Skin Fibrosis. Molecular Medicine 20(1): 410-416.

16. Dömötör E, Benzakour O, Griffin JH, Yule D, Fukudome K, et al. (2003) Activated protein $\mathrm{C}$ alters cytosolic calcium flux in human brain endothelium via binding to endothelial protein $\mathrm{C}$ receptor and activation of protease activated receptor-1. Blood 101(12): 4797-4801.

17. Marshall JC (2003) Such stuff as dreams are made on: Mediator-directed therapy in sepsis. Nature Reviews Drug Discovery 2(5): 391-405.

18. Frateschi S, Camerer E, Crisante G, Rieser S, Membrez M, et al. (2011) PAR2 absence completely rescues inflammation and ichthyosis caused by altered CAP1/Prss8 expression in mouse skin. Nature Communications 2: 161 .

19. Tsujii K, Andoh T, Ui H, Lee JB, Kuraishi Y (2009) Involvement of Tryptase and Proteinase-Activated Receptor-2 in Spontaneous ItchAssociated Response in Mice With Atopy-like Dermatitis. Journal of Pharmacological Sciences 109(3): 388-395.

20. Shpacovitch V, Feld M, Bunnett NW, Steinhoff M (2007) Proteaseactivated receptors: Novel PARtners in innate immunity. Trends in Immunology 28(12): 541-550.

21. Demerjian M, Hachem JP, Tschachler E, Denecker G, Declercq W, et al. (2008) Acute Modulations in Permeability Barrier Function Regulate Epidermal Cornification: Role of Caspase-14 and the Protease-Activated Receptor Type 2. The American Journal of Pathology 172(1): 86-97.

22. Lee SE, Jeong SK, Lee SH (2010) Protease and protease-activated receptor-2 signaling in the pathogenesis of atopic dermatitis. Yonsei medical journal 51(6): 808-822.

23. Grant AD, Cottrell GS, Amadesi S, Trevisani M, Nicoletti P, et al. (2007) Protease-activated receptor 2 sensitizes the transient receptor potential vanilloid 4-ion channel to cause mechanical hyperalgesia in mice. The Journal of Physiology 578(3): 715-733.

24. Rattenholl A, Steinhoff M (2008) Proteinase-activated receptor-2 in the skin: Receptor expression, activation and function during health and disease. Drug News Perspect 21(7): 369-381.

25. Xue M, Smith MM, Little CB, Sambrook P, March L, et al. (2009) Activated protein C mediates a healing phenotype in cultured tenocytes. J Cell Mol Med 13(4): 749-757.

26. Herron GS, Banda MJ, Clark EJ, Gavrilovic J, Werb Z (1986) Secretion of metalloproteinase by stimulated capillary endothelial cells. II. Expression of collagenase and stromelysin activities is regulated by endogenous inhibitors. Journal of Biological Chemistry 261(6): 28142818.

27. (2021) USNLM: Primer-BLAST: A tool for finding specific primers. In: Medicine USNLo (Edt.)., National Center for Biotechnology Information.

28. Xue M, Thompson P, Kelso I, Jackson C (2004) Activated protein C stimulates proliferation, migration and wound closure, inhibits apoptosis and upregulates MMP-2 activity in cultured human keratinocytes. Exp Cell Res 299(1): 119-127.

29. Xue M, Dervish S, Chan B, Jackson CJ (2017) The endothelial protein C receptor is a potential stem cell marker for epidermal keratinocytes. Stem Cells 35(7): 1786-1798. 
30. Peiris TH (2016) The Akt signaling pathway is required for tissue maintenance and regeneration in planarians. BMC Developmental Biology.

31. Xiao W, Tang H, Wu M, Liao Y, Li K, et al. (2017) Ozone oil promotes wound healing by increasing the migration of fibroblasts via PI3K/Akt/ mTOR signaling pathway. Bioscience Reports 37(6): BSR20170658.

32. Karrasch T, Spaeth T, Allard B, Jobin C (2011) PI3K-Dependent GSK $_{3} ß($ Ser9)-Phosphorylation Is Implicated in the Intestinal Epithelial Cell Wound-Healing Response. PloS one 6(10): e26340.

33. Bedi A, Kovacevic D, Hettrich C, Gulotta LV, Ehteshami JR, et al. (2010) The effect of matrix metalloproteinase inhibition on tendon-to-bone healing in a rotator cuff repair model. Journal of shoulder and elbow surgery 19(3): 384-391.

34. Creemers LB, Jansen IDC, Docherty AJP, Reynolds JJ, Beertsen W, et al. (1998) Gelatinase A (MMP-2) and cysteine proteinases are essential for the degradation of collagen in soft connective tissue. Matrix Biology $17(1): 35-46$

35. Foda HD, Zucker S (2001) Matrix metalloproteinase in cancer invasion, metastasis and angiogenesis. Drug Discov Today 6(9): 478-482.

36. Bernard GR, Vincent JL, Laterre PF, LaRosa SP, Dhainaut JF, et al. (2001) Efficacy and Safety of Recombinant Human Activated Protein C for Severe Sepsis. New England Journal of Medicine 344(10): 699-709.

37. Montes R, Puy C, Molina Buey E, Hermida J (2012) Is EPCR a multi-ligand receptor? Pros and cons, pp. 815-826.

38. Jackson CJ, Xue M (2008) Activated protein C--an anticoagulant that does more than stop clots. Int J Biochem Cell Biol 40(12): 2692-2697.

39. Whitmont K, McKelvey KJ, Fulcher G, Reid I, March L, et al. (2015) Treatment of chronic diabetic lower leg ulcers with activated protein C: A randomised placebo-controlled, double-blind pilot clinical trial. International Wound Journal 12(4): 422-427.

40. Whitmont K, Reid I, Tritton S, March L, Xue M, et al. (2008) Treatment of Chronic Leg Ulcers With Topical Activated Protein C. JAMA Dermatology 144(11): 1479-1483.

41. Wijewardena A, Vandervord E, Lajevardi SS, Vandervord J, Jackson CJ (2011) Combination of Activated Protein C and Topical Negative Pressure Rapidly Regenerates Granulation Tissue Over Exposed Bone to Heal Recalcitrant Orthopedic Wounds. The International Journal of Lower Extremity Wounds 10(3): 146-151.

42. Bouwens EAM, Stavenuiter F, Mosnier LO (2013) Mechanisms of anticoagulant and cytoprotective actions of the protein $\mathrm{C}$ pathway. J Thromb Haemost 11 Suppl 1(01): 242-253.

43. Julovi SM, Xue M, Dervish S, Sambrook PN, March L, et al. (2011) Protease activated receptor- 2 mediates activated protein $\mathrm{C}$-induced cutaneous

ISSN: 2574-1241

DOI: 10.26717/BJSTR.2021.39.006341

Meilang Xue. Biomed J Sci \& Tech Res

This work is licensed under Creative Commons Attribution 4.0 License

Submission Link: https://biomedres.us/submit-manuscript.php wound healing via inhibition of p38. The American journal of pathology 179(5): 2233-2242

44. Shen K, Murphy CM, Chan B, Kolind M, Cheng TL, et al. (2014) Activated protein $\mathrm{C}$ (APC) can increase bone anabolism via a protease-activated receptor (PAR)1/2 dependent mechanism. Journal of Orthopaedic Research 32(12): 1549-1556.

45. Gur Cohen S, Itkin T, Chakrabarty S, Graf C, Kollet O, et al. (2015) PAR1 signaling regulates the retention and recruitment of EPCR-expressing bone marrow hematopoietic stem cells. Nature Medicine 21: 1307-1317.

46. Yoshida K, Akita N, Okamoto T, Asanuma K, Uchida A, et al. (2018) Activated protein $\mathrm{C}$ suppresses osteoclast differentiation via endothelial protein C receptor, protease-activated receptor-1, sphingosine 1-phosphate receptor, and apolipoprotein E receptor 2. Thrombosis Research 163: 30-40.

47. Zhao P, Metcalf M, Bunnett NW (2014) Biased signaling of proteaseactivated receptors. Front Endocrinol (Lausanne) 5: 67-67.

48. Sun HB, Andarawis Puri N, Li Y, Fung DT, Lee JY, et al. (2010) Cycledependent matrix remodeling gene expression response in fatigueloaded rat patellar tendons. J Orthop Res 28(10): 1380-1386.

49. Garofalo R, Cesari E, Vinci E, Castagna A (2011) Role of Metalloproteinase in Rotator Cuff Tear. Sports Medicine and Arthroscopy Review 19(3): 207-212.

50. Choi HR, Kondo S, Hirose K, Ishiguro N, Hasegawa Y, et al. (2002) Expression and enzymatic activity of MMP-2 during healing process of the acute supraspinatus tendon tear in rabbits. Journal of Orthopaedic Research 20(5): 927-933.

51. Oshiro W, Lou J, Xing X, Tu Y, Manske PR (2003) Flexor tendon healing in the rat: a histologic and gene expression study. Journal of Hand Surgery 28(5): 814-823.

52. Jackson MT, Moradi B, Smith MM, Jackson CJ, Little CB (2014) Activation of matrix metalloproteinase 2,9 , and 13 by activated protein $C$ in human osteoarthritic cartilage chondrocytes. Arthritis Rheumatol 66(6): 15251536

53. Sharma P, Maffulli N (2005) Tendon Injury and Tendinopathy: Healing and Repair. JBJS 87(1): 187-202.

54. Jakob F, Ebert R, Rudert M, Nöth U, Walles H, et al. (2012) In situ guided tissue regeneration in musculoskeletal diseases and aging. Cell and Tissue Research 347(3): 725-735.

55. Yang G, Rothrauff BB, Tuan RS (2013) Tendon and ligament regeneration and repair: Clinical relevance and developmental paradigm. Birth Defects Research Part C: Embryo Today: Reviews 99(3): 203-222.

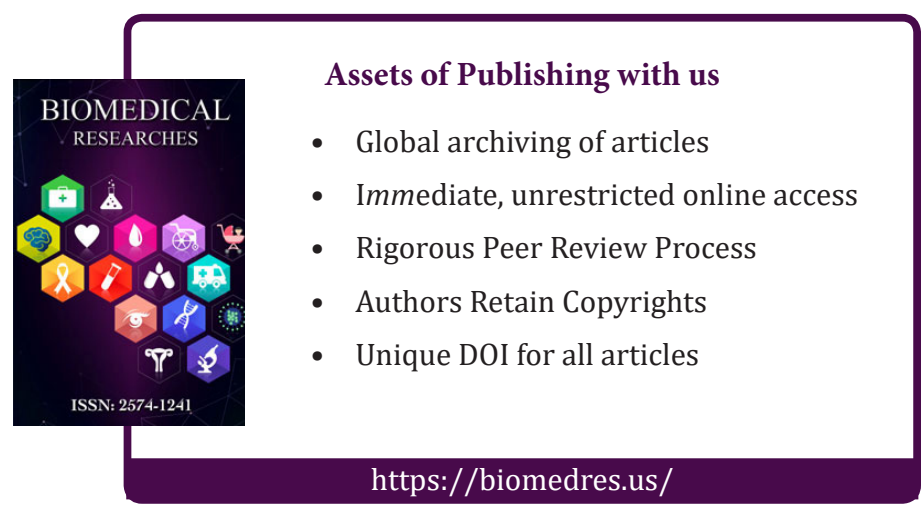

